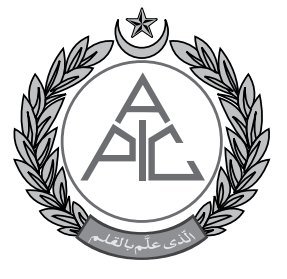

\section{Intensive Care Unit design; from advance to basic}

\author{
Mohsin Nazir Butt, FCPS ${ }^{1}$, \\ Muhammad Faisal Khan, MCPS, FCPs, EDIC, MSc ${ }^{1}$
}

\begin{abstract}
Optimum ICU design has pivotal role in critical care delivery that has major impact on physical and psychological health of the patients, physicians and other related staff. Its structure formation is complex and demands the dedicated involvement of not only care providers but also a trained and multi-professional team of architect, engineer and information technologists, etc.

This paper tracks the journey from traditional design to recent advances in building the intensive care unit. The limitations in ICU design observed in the lower to middle income countries will also be discussed in this review. Specialist hospital architects are scarce in these countries and the ordinary civil engineering does not impart adequate coaching on matters related to lay-out plans as well as the various minute details about fittings and provisions. Hence, it becomes imperative for the anesthesiologists and other healthcare providers to come to guide and assistance to the architects involved in designing the blue prints. It may only be possible if they have adequate knowledge and professional experience.
\end{abstract} Department of Anesthesiology,
Aga Khan University Hospital, Karachi (Pakistan)

Correspondence:

Dr. Mohsin Nazir Butt, Assistant Professor, Department of Anesthesiology, Aga Khan University Hospital, Stadium Road, P. O. Box 3500, Karachi 74800, (Pakistan); Phone: +92 321 2227083; Email: mohsin.nazir@aku.rdu

Received: 23 Oct 2018

Reviewed: 25 Oct 2018

Accepted: 25 Oct 2108

Key words: Intensive Care Unit; Intensive care; Design

Citation: Butt MN, Khan MF. Intensive Care Unit design; from advance to basic. Anaesth Pain \& Intensive Care 2018;22 Suppl 1:S17-S20

\section{INTRODUCTION}

Intensive Care Unit (ICU) is highly sophisticated and specialized area which is a purposefully designed, adequately staffed, appropriately located, and well equipped unit to manage critically ill patients in the hospital. ICU facilitates the prevention, diagnosis and multi-disciplinary management of debilitating patients. It can work as an isolated department but should have very clear operational policies. In the following discussion, description of a standard ICU design will be stated and followed by the current situation of intensive care design in a developing country.

Optimal design of an ICU can help to improve patient care, reduce avoidable medical errors and length of ICU stay and ultimately reduce the patients' cost. The optimal design of an ICU requires evidence based best practice guidelines, design standards and building codes. ${ }^{1}$ Staff satisfaction is also required for the optimal working of an ICU. Satisfaction of staff with the work environment has been shown to correlate not only to the patients' satisfaction but also to the improved retention and commitment of staff. ${ }^{2}$

\section{Advancement in ICU design}

ICU design is complex and a specialized design team is required for this purpose. The design team should include (i) highly experienced design professional architects, (ii) engineers and technology planners of medical equipment, information technology, (iii) institution/hospital administration and finance department, (iv) clinically oriented medical team members including physicians, nurses, infection control specialists and pharmacists, (v) material management and (vi) environment service representatives. In the initial planning part of the project, the certification of architects with LEED (Leadership in Energy and Environmental Design) may be helpful. 
Structurally, the intensive care unit consists of following four major zones:

Patient care zone consists of patient rooms and adjacent areas; its primary function is to provide the direct care of patients.

Clinical support zone consists of functions closely related to the direct patient care.

Unit support zone refers to the areas of unit for administrative, materials management, and staff support.

Zone of family support refers to the areas in the ICU, designed to support families of the patients' and other visitors. $^{3}$

The direct patient care unit should have some specifications. Some of them are discussed below. About the patient care zone of an ICU, it has been demonstrated that single rooms are superior to multi-bed rooms in terms of enhanced patient safety and privacy. ${ }^{4}$ The clear floor area of a single patient room should not be less than four feet at the head and foot sides of bed and should not be less than six feet on each side of the standard critical care bed. ${ }^{5}$ The space around the bed, allows room for services to the bedside like portable x-ray imaging, echocardiography, ultrasound etc. The door system should be appropriately sized for the rapid movement of patients, equipment and crash carts in case of emergency. The glass sliding doors with breakaway capacity are preferred because they provide additional width and visibility of the patients. ${ }^{3}$ Each patient care unit should have a visual access to the outdoor. For this purpose, an appropriate sized window should be present in each patient care unit. The window system and its covers should be easily cleaned in accordance with the standard infection control guidelines. Providing an outside view to the patient may decrease anxiety, improve patient care and enhance patients' comfort. ${ }^{6}$ A single patient care unit should contain a designated bed for critically ill patient, one chair for patient, one chair for the visitor, soiled linen collection hamper, trash bin, container for sharp wastes and a container for other waste materials. The options for mounting and configuring of medical utility outlets include flat headwall system, fixed column system, suspended column system, boom configurations system and combinations or hybrids of these systems may be appropriate. ${ }^{3}$ The medical gas outlets, vacuum, and electrical outlets should be accessible from each side of the patient bed and it should be arranged to provide enough room for multiple, procedures simultaneously. ${ }^{3}$ The patient care units' temperature should be adjustable and can be controlled by the patient care team. Hand hygiene facility should be emphasized in priority. For proper hand hygiene, hand washing sink with soap, water and alcohol gel system for maximum performance. Water and drain connections for dialysis or continuous renal replacement therapy should be separate from hand washing sinks and located so that dialysis equipment can be placed on either side of the patient's bed. ${ }^{3}$

Clinical support functions include all unit functions related to diagnosis and treatment of patients. An emergency eyewash station for ICU staff should be present to address the issue of inadvertent exposure of hazardous body fluids. The teamwork of physician specialist, pharmacists, respiratory therapist, dietician and other health professionals have been shown to improve the quality of patient care. ${ }^{7}$ A central location is required for the interdisciplinary team interaction and centralized activities. A link has been shown between the poor visualization of patients by nursing and doctors to their mortality rates. ${ }^{8}$ So, the ICU design should be appropriate for proper visualization of patients' body and face through the ICU corridor and from interdisciplinary team discussion area. Centralized monitoring should be placed to enable staff and nurses for convenient monitoring of the patients from different vantage points. The concept of electronic ICU is also emerging with remote monitoring of the critically ill patients. Through this technology, the patient trend data can be accessed by the physician at any remote location in an emergency situation. ${ }^{9}$ For an advanced electronic ICU model, video observation, physiologic monitoring and communication links should be provided in each patient room. Computer based order entry system is an innovation and emerging technology. A dedicated computer panel and telephone should be within easy reach of ICU staff. An area for documentation and review of record should be designed to minimize distractions and errors. The pharmacy services should be easily accessible and available round the clock. A designated area for point of care pharmacy with a dedicated computer terminal and workstation should be placed in ICU. An ICU must has a 24/7 access to the clinical laboratory and radiologic imaging services. A space may be designated to the point of care testing equipment and portable imaging machines. A space for respiratory therapy office, and storage of respiratory support equipment should be within or near to ICU should be designed. The patients' room should also be designed for different invasive minor procedures. A dedicated space for patient nourishment must be provided in ICU. ${ }^{3}$ The mechanism of transporting patients within ICU and out of ICU for different procedures or surgeries 
should also be emphasized. It must consider both horizontal and vertical paths of transportation. The patient elevator should be within ICU or near to ICU, which should be spaced enough to accommodate patient bed, monitoring and other transport equipment. Other considerations for the patient transport mechanism include transport corridors width and door swing directions. These should be adequately designed to transport critically ill patients with attached necessary equipment to different clinical areas for extremely essential interventions and specialized radiological procedures. ${ }^{3}$

The unit support zone mainly comprises of areas for administrative and logistics support functions. The members of the team may require space for offices, management meetings, education and clinical purposes. This unit should also include the space for consultation with families. A well designed material management and housekeeping services must be in placed. Supplies of all kind may be transported via dedicated lifts for easy and immediate supply services. This unit also includes separate clean and dirty utility rooms. The unit should also provide adequate storage space for the housekeeping equipment and supplies. Staff oncall rooms, lounge, rest rooms and space for lockers are also included in the unit support zone. ${ }^{10}$

The family support zone includes the space outside of the patient room for family members and other visitors. Family support has been recognized as a significant factor in reducing morbidity and recovery of critically ill patients. ${ }^{11}$ Family lounge, family communication room, meditation room and place for family and visitors' nourishment must be near to or adjacent to the ICU. If possible, a family sleep room and family laundry services should also be provided in the family support zone of ICU.

\section{Limitation in Lower and Middle Income Countries}

The current situation in the developing world or low-middle income countries is different as compared to the standards derived from the design and construction of intensive care units in developed world and standards provided by the world societies of critical care medicine. The difference is more pronounced in public sector tertiary care hospitals of the developing countries as compared to the private tertiary care hospitals. The main reasons behind are inadequate resources availability including medical and design experts available in these countries and hence the construction of intensive care unit is usually on weak planning grounds. Near to no functional planning concept has been incorporated in the construction of an ICU. Another important limitation in achieving the design standards are the institutional administration's vision or government stakeholder's vision of establishing a costly unit with marginal revenue generation. But the thinking of administration on more medical ground rather on business grounds must enhance the provision of specialized service delivery and specialized patient care concept of critically ill. It compels the stakeholders to brainstorm regarding stepwise achievement of ICU design and service standards.

In this part of the world, most of the standards described above are missing in government sector public hospital. If we see the private sector hospitals in Pakistan, few large tertiary care hospitals have achieved some standards described by intensive care societies of the developed world. These private hospitals have well defined direct patient care zones and clinical support zones. But the zones of staff support and family support are usually not well spaced or might not exist. In direct patient care zone, hospitals have single patient room or four to six patient bed rooms are available with most of the necessary monitoring and support equipment. Some hospitals are deficient in adequate space availability for portable imaging and other bed side procedures. The construction standards in term of doors, windows and natural light accessibility of most of the ICUs in developing world usually deviate from the recommended standards. Patient visualization from the main staff counter and centralized monitoring are available in very few private sector hospitals of Pakistan while the concept of electronic ICU with remote monitoring is still in the planning phase. Pharmacy system is mostly computer integrated with well-designed central pharmacy software and designated users of these software. While in supplies (including pharmacy supplies) and material management services, most of these are still manually organized. No computerized entry system and electrically mediated supply system (with designated lifts) are available till date in most of the ICUs of developing world. In staff support zone, some facilities are available in very few private ICUs while the family support zones of most of the ICUs don't have enough facilities for families and other visitors.

\section{CONCLUSION}

Planning and design of critical unit has a significant impact on the organizational performance. It also enhances the clinical outcome of critically ill patients and overall cost effectiveness. The organizations involved in the planning and construction of intensive care unit must have professional design and construction experts' teams, who have experience in construction of number of medical facilities. They 
collaborate with the users and make key design decision according to the current best evidence. In the developing world, they take a decision to establish a critical care unit without realizing the associated needs of the staff and facilities. Its necessity and need in the society should first be emphasized by the critical care physicians to the stakeholders. The training of critical care should be readily available for postgraduates and formally recognized by the central postgraduate educational bodies. So that the field of critical care can progress and standards are laid down not only in patient care but also for the design of an ICU.

Conflict of interest: The authors declare that they have no conflict of interest.

Authors' contribution: Both authors took part in the preparation of the manuscript

\section{REFERENCES}

1. Hamilton D, Thompson D. What's new in ICU design. Critical Connections. Society of Critical Care Medicine. 2005:1-10.

2. Donchin Y, Seagull FJ. The hostile environment of the intensive care unit. Current opinion in critical care. 2002;8(4):316-20.

3. Thompson DR, Hamilton DK, Cadenhead CD, Swoboda SM, Schwindel SM, Anderson DC, et al. Guidelines for intensive care unit design. Critical care medicine. 2012;40(5):1586-600.

4. Teltsch DY, Hanley J, Loo V, Goldberg P, Gursahaney A, Buckeridge DL. Infection acquisition following intensive care unit room privatization. Archives of internal medicine. 2011;171(1):328.

5. Institute FG. Guidelines for design and construction of health care facilities: ASHE (American Society for Healthcare Engineering of the American Hospital Association); 2010.

6. Ulrich RS, Zimring C, Zhu X, DuBose J, Seo H-B, Choi Y-S, et al. A review of the research literature on evidencebased healthcare design. HERD: Health Environments Research \& Design Journal. 2008;1(3):61-125.

7. Durbin CG. Team model: advocating for the optimal method of care delivery in the intensive care unit. Critical care medicine. 2006;34(3):S12-S7.

8. Leaf DE, Homel P, Factor PH. Relationship between ICU design and mortality. Chest. 2010;137(5):1022-7.

9. Yoo EJ, Dudley RA. Evaluating telemedicine in the ICU. JAMA. 2009;302(24):2705-6.

10. McEvoy RD, Lack LL. Medical staff working the night shift: can naps help? Medical journal of Australia. 2006;185(7):349-50.

11. Bay EJ, Kupferschmidt B, Opperwall BJ, Speer J. Effect of the family visit on the patient's mental status. Focus on critical care. 1988;15(1):11. 